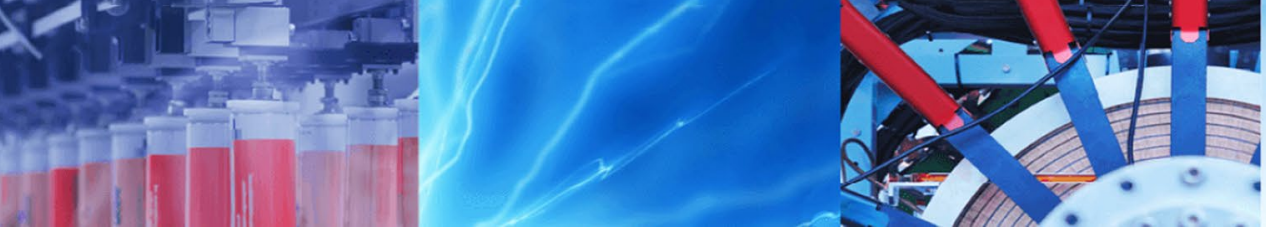

Research Article

\title{
Experimental modal analysis using laser vibrometer and finite element modeling of milling machine arbor
}

\author{
Jai Kumar Sharma ${ }^{1}$ D . Sandeep Kumar Parashar ${ }^{1}$
}

(c) Springer Nature Switzerland AG 2019

\begin{abstract}
Experimental modal analysis has received a lot of consideration in recent days for dynamic analysis of complicated engineering structure and machine tools. It is a process which is used to determine the inherent dynamic properties of structure such as damping, mode shapes and natural frequencies. The experimental modal analysis benefits in design of all types of structures including automotive components, aircraft components, spacecraft, computers and tennis rackets and golf clubs etc. The present study deals with the experimental investigation of free vibration of milling machine arbor. Experimental modal analysis of milling machine arbor is carried out by using laser vibrometer for measurement and impact hammer for excitation. The experimental results are compared with the numerical predictions obtained using finite element modeling software ANSYS workbench 14.5. The scope of present work is to understand and investigate the modal parameters of milling machine arbor in the form of natural frequency and mode shape for robust design.
\end{abstract}

Keywords Experimental modal analysis · Laser vibrometer $\cdot$ Finite element modeling $\cdot$ Milling machine arbor

\section{Introduction}

In the past two decades the experimental modal analysis (EMA) has become a major tool for determining, improving and optimizing the dynamic characteristics of engineering structures and machine tools. The modal parameter of the machine components in the form of natural frequency, damping factor and mode shapes are obtained in the process. In the experimental modal analysis, an excitation or external force is applied in a controlled manner at a number of locations so as to induce the vibrations of the test structure. Then the vibration response data is collected with the help of suitable transducer. The collected vibration data is then analysed to extract the modal parameters, namely, modal damping, mode shapes and natural frequencies.

The finite element modeling (FEM) has become a powerfull tool for dynamic analysis of a wide range of engineering structure and components. It is a computer approach which provides fairly accurate approximate solution of engineering problems. Finite element has three major stages, i.e. the pre-processor, the solution, and the post processor stage. In the pre-process stage a CAD model of milling machine arbor is required to be generated. The $C A D$ model of engineering structure and machine components is usually developed on CAD software like Solid works, CATIA, Pro/E and ANSYS workbench. Mesh generation is carried out after developed dynamic model of arbor. After that the proper material property to each model is assigned and finally fixed-free and free-free boundary conditions are applied to the arbor (Fig. 1). It is necessary to apply correct boundary conditions in FEM to get without error results.

The finite element modeling is extensively used in industry for producing an excellent representation of a true engineering structure. However, for complex engineering structure and components due to limitation of computer or method, application of finite element modeling alone can lead to an error. The combination of both experimental modal testing and finite element modeling

$\triangle$ Jai Kumar Sharma, jaikumarsharma94@gmail.com| ${ }^{1}$ Department of Mechanical Engineering, Rajasthan Technical University, Rawatbhata Road, Kota, Rajasthan 324010, India. 


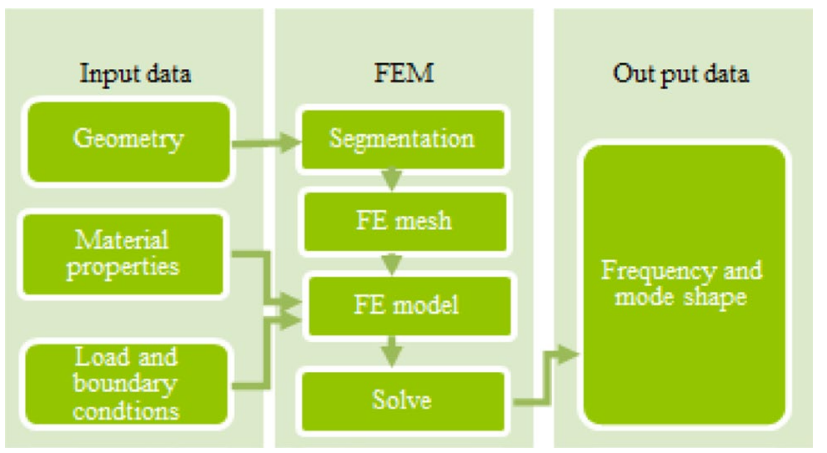

Fig. 1 Finite element modeling process for dynamic analysis

is widely used to determine dynamic properties of complicated structure with minimum error.

The milling machine is a power-driven machine that cuts the metal using the multi tooth rotating cutter. The milling machine is constructed in such a way that the workpiece is fed under the rotary cutter, means the workpiece is fixed on the table and the tool is rotating. Depending upon the position of spindle and table, the knee and column type milling machine is classified as either horizontal or vertical [1]. The spindle of milling machine is power driven. An arbor fits into the spindle using the draw bolts. One or more cutters are mounted on the arbor by placing spacing collars between them. The other end of the arbor is mounted in bearing supports.

Several researchers have done modal analysis through experimental and FEM both to predict the dynamic behavior of engineering components. Patwari et al. [2] presented a systematic process and details of the use of experimental testing and finite element modeling technique to determine dynamic characteristics of milling machine vertical machining centre. The FEM software ABAQUS was used to extract the natural frequency and shape of vibration modes. Pedrammehr et al. [3] performed the modal testing of the milling machine components through FEM and experiment. For this purpose, the CAD model of milling machine was developed on CATIA and then natural frequencies and mode shape of the milling machine tool structure were obtained through finite element modelling software ANSYS workbench. Xiao et al. [4] determined the modal parameters in the form of mode shapes, natural frequency, and structure damping of MIKRON UCP 710 high-speed milling centre through finite element modal analysis and experimental modal analysis. In their work, they used the integral polynomial recognition method and vector analysis technique to determine modal parameters. Jamil et al. [5] determined the natural frequencies of milling machine tool. For this purpose the three dimensional model of the machine tool's component was made using CAD software and FEM software. The milling machine tool was excited by an impact hammer and the reaction of the excited vibration is recorded. In the end, the results of both FEM and experiment were compared. In other work Jamil et al. [6] also obtained the natural frequencies and mode shapes of different milling machine tools. The free-free boundary conditions in milling machine spindle was used to determine modal parameters by Cao and Altintas [7]. Rong et al. [8] determined the Eigenvalue of structure using a combination of finite element method and transfer matrix method. Barone et al. [9] performed the experimental modal analysis on a cantilever plate and turbine blade using pseudo-stereo DIC system. Galson et al. [10] determined the natural frequencies and damping of lithium-ion polymer batteries by using Laser Doppler Vibrometery. Olsen et al. [11] reduced the number of pseudo channels to avoid over fitting. Catillo et al. [12] determined the modal parameters of submersible pump. The impact hammer was used for excitation and the model of submersible pump was developed using finite element modeling software.

In all the previous published work so far the experimental testing has not been used to obtain the dynamic properties (natural frequency and mode shape) of milling machine arbor. The present study deals with the experimental investigation of free vibration of milling machine arbor. The experimental results are compared with numerical predictions using FEM ANSYS workbench 14.5. The accurate analysis of the dynamic properties herein may help in improved design of the machine part.

\section{Experimental modal analysis}

In the last few decades the researcher and scientists have shown curiosity in good understanding of the dynamic characteristics of the structure and machine tools by investigating the modal testing parameters in the form of natural frequencies, mode shapes, and damping ratio. It is referred to as modal testing [13]. Modal testing is based on evaluating modal testing parameters of a linear, time invariant system in route of experimental approaches [14]. The knowledge about the modal parameter of structure and machine tools may be helpful in various purposes such as structural modification [15], monitoring of structural health [16] and updating of model [17].

\subsection{Experimental set-up}

The basic experimental set-up used in the present work is shown in Fig. 2. The experimental set-up used primarily consists of three devices namely laser vibrometer (Polytec, NLV-2500-5), digital oscilloscope (NB207C1) and the impact hammer.

The laser vibrometer (NLV-2500-5) is a unique device for non-contact acquisition of vibrations. The measurement 
Fig. 2 Basic experimental set-up



range of laser vibrometer for vibration amplitude and frequency is so large that it covers nearly all scientific and technical applications. Vibrometer is capable to generate both displacement and velocity signals from the measurement [18]. To determine the natural frequencies of arbor the experimental set-up is prepared. The arbor (without collar) was properly hanged on thin wires to get free-free boundary conditions as shown in Fig. 3. For the cantilever boundary condition the arbor was fixed at one end. Though in actual usage conditions the arbor is not in the free-free condition on machine. But the purpose of this modal testing is to validate the FE model using the experimental data. So that the same FE model can be used with assurance for more complicated boundary conditions. The sensor head was fixed on tripod to get the required distance between the sensor head and the arbor. The

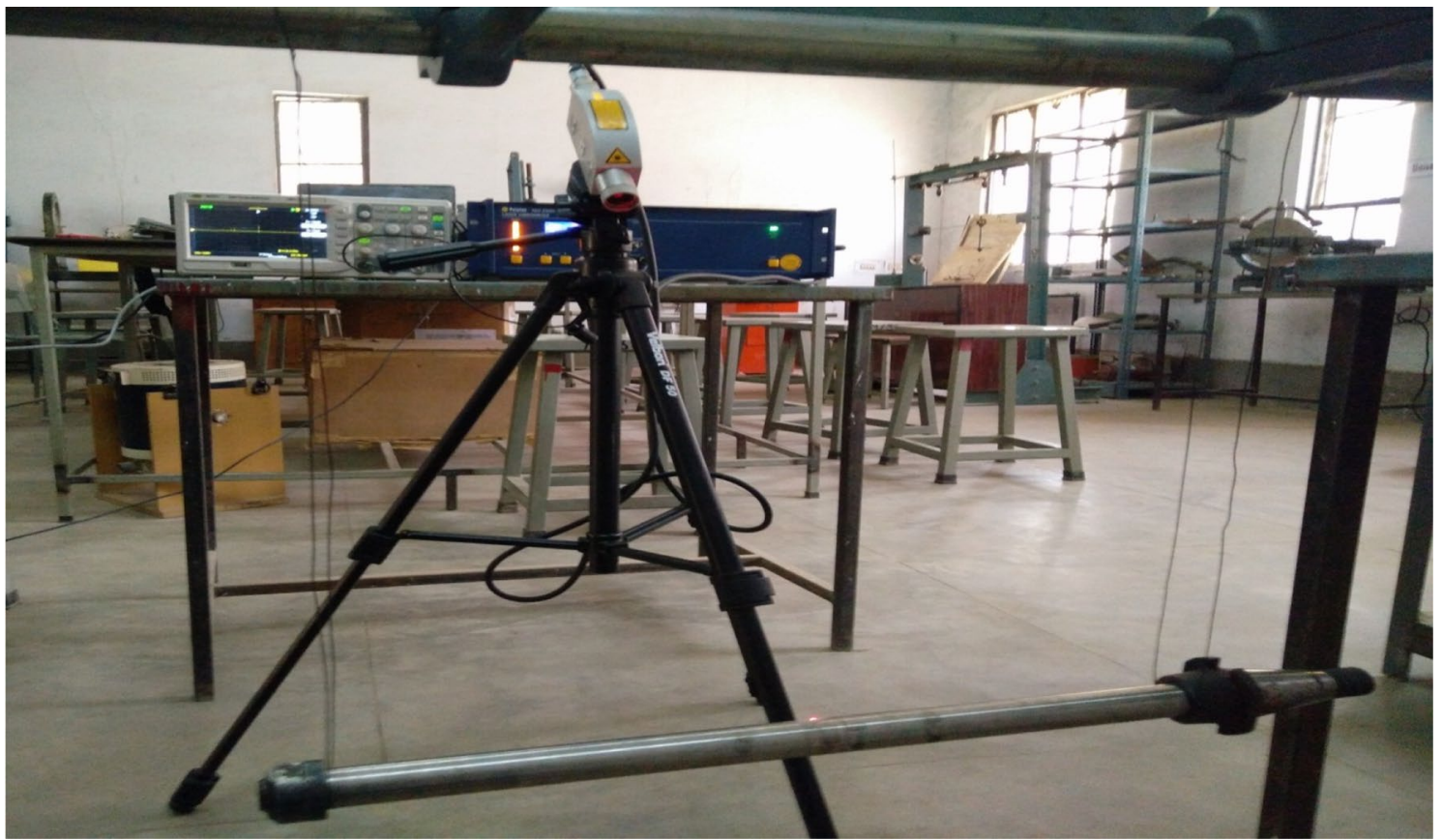

Fig. 3 Experimental set-up for milling machine arbor 
connections between sensor head, laser vibrometer, and digital oscilloscope were ensured before the excitation.

\subsection{Experimental procedure}

The arbor is excited at selected points (middle of the arbor) by the means of an impact hammer in free-free and cantilever boundary conditions. The resulting response is picking up by the laser vibrometer. The signals from the laser vibrometer are delivering to the digital oscilloscopes (NB207C1) in which data are prepared. From the digital oscilloscope the signals in time domain are saved in a USB drive. These time domain signals are transformed into frequency domain using the Fast Fourier Transformation with the help of a MATLAB program. At the time of striking with the impact hammer precaution is taken to make the stroke perpendicular to the surface of the arbor as the aim here is to determine natural frequencies of the arbor only in bending.

\subsection{Signal processing}

In order to determine the modal testing parameters, the digital signal processing of measured data is a very crucial step in modal analysis. Signal processing is one of the major areas of electronics engineering where clear understanding of time-frequency relationship is important [19].

Table 1 Experimental results of milling machine arbor

\begin{tabular}{lll}
\hline End conditions & No. of mode & $\begin{array}{l}\text { Experimental } \\
\text { natural frequency } \\
(\mathrm{Hz})\end{array}$ \\
\hline Free-free & Mode 1 & 271 \\
Fixed-free & Mode 2 & 813 \\
\hline
\end{tabular}

The transformation of data from time domain spectrum to frequency domain spectrum is important both in measurement and in the modal parameter estimation.

First the measured signal in time analogue form is converted into digital form. A signal is said to be an analoguetime signal if it is continuous along both $x$-and $y$-axis and the signal which is discrete along $x$-axis and continuous along $y$-axis is called discrete-time signal. The process that converts the signal from the continuous time to discretetime is called the sampling. Sampling involves measuring the value of the signal at regular intervals of time and each value is referred to as a sample. In the present study 20,482 samples were taken at a sampling rate of $\left(8 \times 10^{-5}\right)$. The sampling rate is defined as the speed at which the signal data is collected, and it is expressed in number of samples per second. Any analogue signal $x_{c}(t)$ can be converted to discrete-time form by sensing value of $x_{c}(t)$ at regular interval of time $n T s$ to obtain sequence $x(n)$. Ts are called the sampling interval and this type of sampling done at regular intervals is called uniform sampling. It is specified by sampling frequency $\mathrm{fs}=(1 / \mathrm{Ts})$ in hertz rather than the sampling period in second [20]. The theoretical limit for the maximum frequency is called Nyquist frequency and it is defined as one half of the sampling frequency. A program written in MATLAB is used for Fast Fourier Transform and to obtain the natural frequencies from the measured signal.

\subsection{Results}

Table 1 shown the results obtained from the experiment in free-free and fixed free boundary conditions. The time domain spectrum and frequency domain spectrum signals for free-free boundary condition are shown in Figs. 4 and 5 respectively. From the frequency domain signals graphs that are obtained from the MATLAB program using FFT, the



Fig. 4 Time domain signal for arbor in free-free boundary condition 




Fig. 5 Frequency domain signal for arbor in free-free boundary condition

first spike occur at first natural frequency $(271 \mathrm{~Hz})$ and the second spike occur at second natural frequency $(813 \mathrm{~Hz})$ of the milling machine arbor. Under free-free boundary conditions we can determine the natural frequencies of arbor up to second mode using impact hammer easily. Due to very high stiffness of the arbor it is not possible to excite the higher modes of the arbor using the impact hammer. It is to be noted that in case of fixed-free boundary condition only fundamental natural frequency could be obtained from the experiments. The time domain and frequency domain signals for fixed-free boundary condition are shown in Figs. 6 and 7 respectively.

\section{Finite element modeling of milling machine arbor}

The finite element modal analysis of arbor (HMT FN1PH 1109 ) is carried out to determine the modal parameters. The three dimensional modal of arbor is developed on ANSYS workbench design modular software. The geometric parameter used in the analysis are shown in Fig. 8. Firstly drag the modal template to the project schematic from the tool box for the modal analysis of arbor. The nonlinearities in the material characteristics are ignored due to the nature of modal analysis. For the modal analysis, it is critical requirement to define the stiffness and as well as mass. In the



Fig. 6 Time domain signal for arbor in free-free boundary condition 


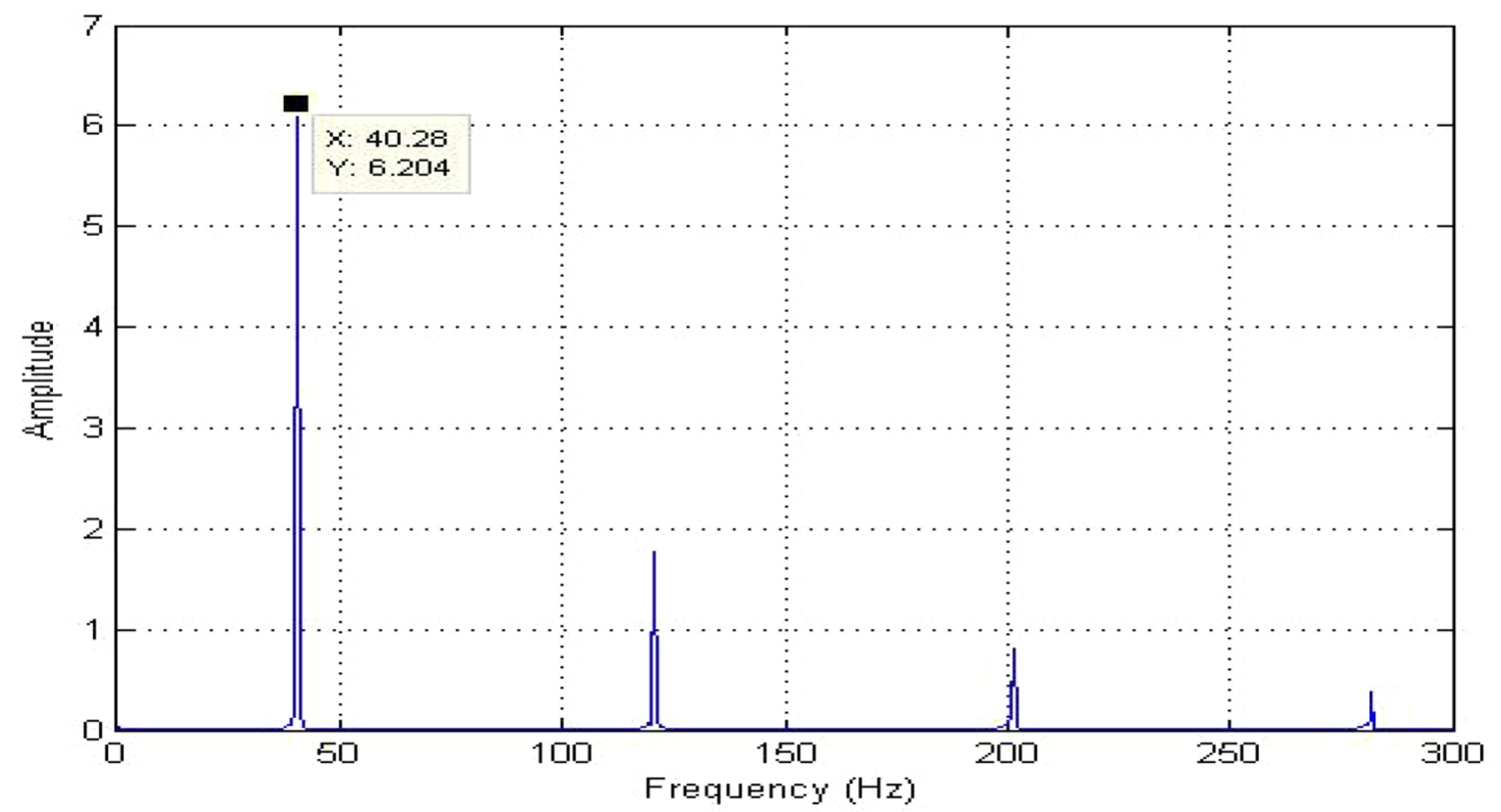

Fig. 7 Frequency domain signal for arbor in free-free boundary condition

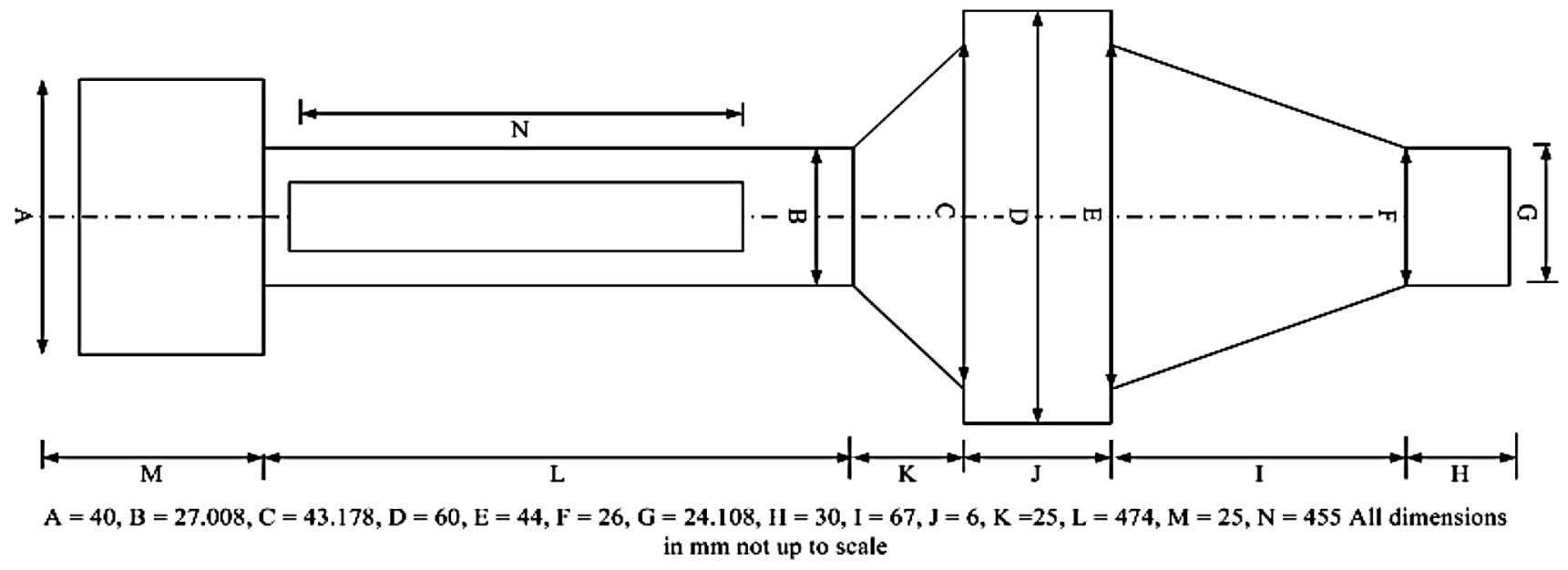

Fig. 8 Schematic diagram of arbor

present study for the finite element model the total number of 13,970 elements and 27,950 nodes are used.

The meshing for the modal analysis of arbor is taken fine in ANSYS work wench and Solid 65 element was taken for analysis. The three-dimensional model of arbor is shown in Fig. 9.

The milling machine arbor is made of mild steel and mechanical properties of mild steel are given in Table 2 . The numerically obtained natural frequencies up to three modes in bending using ANSYS workbench 14.5 are shown in Table 3.
The numerically obtained mode shapes and corresponding natural frequencies of arbor are shown in Fig. 10.

\section{Comparison of FEM and experiment results}

The natural frequencies from the numerical and experimental analysis are obtained using the material properties (Table 2) and dimensions (Fig. 8) of the mild steel arbor in both free-free and fixed free boundary 
Fig. 9 a Arbor and b solid modal of arbor



(a)

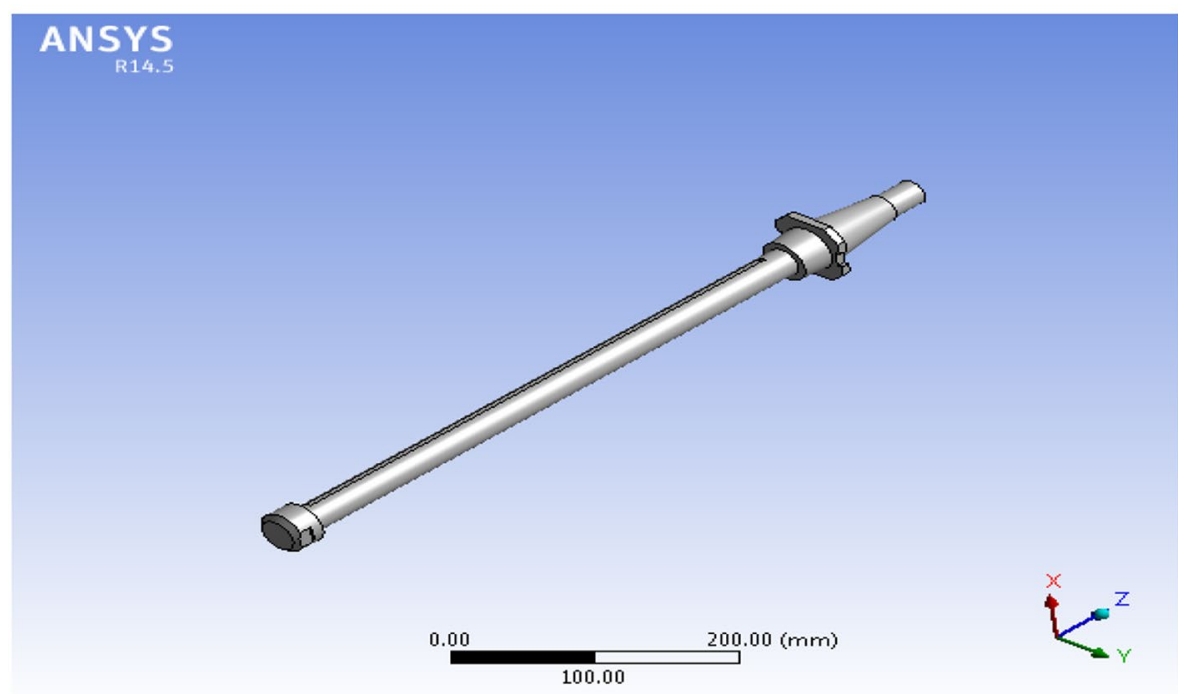

(b)

Table 2 Mechanical properties of mild steel

\begin{tabular}{ll}
\hline Material parameter of arbor & Values \\
\hline$E$ & $2.05 \times 10^{11} \mathrm{~N} / \mathrm{m}^{2}$ \\
$\rho$ & $7830 \mathrm{~kg} / \mathrm{m}^{3}$ \\
$\mathrm{~V}$ & 0.3 \\
\hline
\end{tabular}

conditions. By using the ANSYS workbench 14.5 the numerical natural frequency are obtained and with help of impact hammer excitation method the experimental natural frequencies are obtained. Both numerical and experimental natural frequencies of arbor in free-free and fixed-free boundary conditions are presented in Table 4.
Table 3 Numerically obtained natural frequencies of arbor

\begin{tabular}{llc}
\hline End conditions arbor & No. of mode & $\begin{array}{c}\text { Numerical natural } \\
\text { frequency arbor }(\mathrm{Hz})\end{array}$ \\
\hline Free-free & Mode 1 & 285.3 \\
& Mode 2 & 824.63 \\
Fixed-free & Mode 3 & 1638.1 \\
& Mode 1 & 47.94 \\
& Mode 2 & 273.12 \\
& Mode 3 & 730.09 \\
\hline
\end{tabular}

It can be noticed that in the experiment it was not feasible to excite the third (free-free) and higher modes of arbor using the impact hammer excitation method. The sine sweep test can be more powerful for 
A: Modal

first mode

Type: Total Deformation

Frequency: $285.3 \mathrm{~Hz}$

Unit. $m$

7/17/2016 5:47 PM
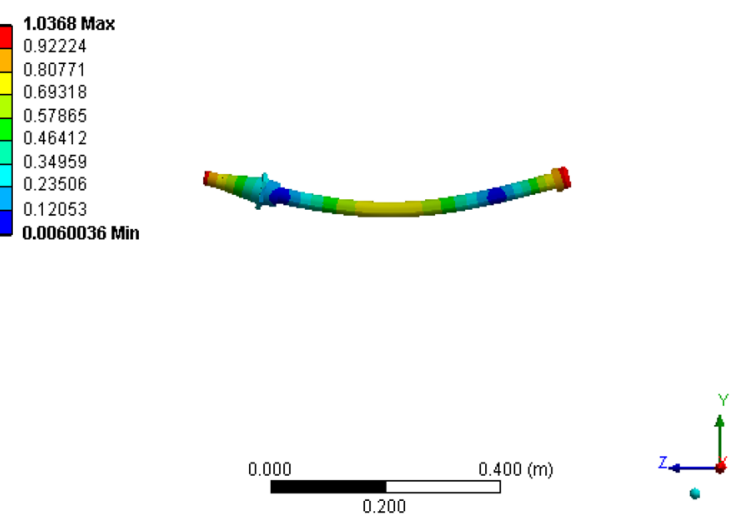

(a)


(b)

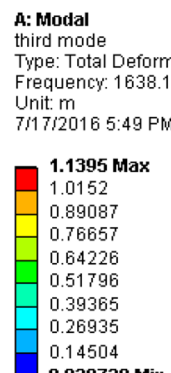

0.020738 hin
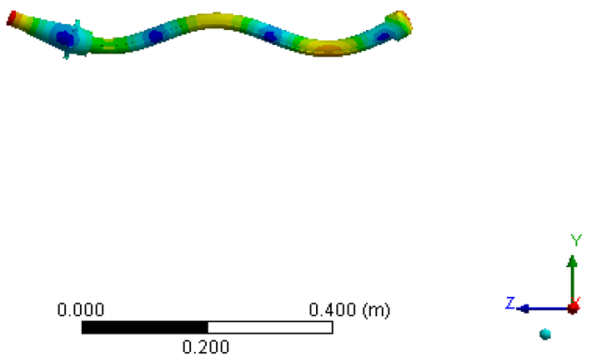

(c)
Table 4 Comparison between the numerical and experimental results

\begin{tabular}{lccl}
\hline $\begin{array}{l}\text { End condi- } \\
\text { tions of } \\
\text { arbor }\end{array}$ & Mode & $\begin{array}{l}\text { Numerical natural } \\
\text { frequency arbor } \\
(\mathrm{Hz})\end{array}$ & $\begin{array}{l}\text { Experimental natural } \\
\text { frequency arbor }(\mathrm{Hz})\end{array}$ \\
\hline Free-Free & Mode 1 & 285.3 & 271 \\
& Mode 2 & 824.63 & 813 \\
Fixed-free & Mode 3 & 1638.1 & - \\
& Mode 1 & 47.94 & 40.28 \\
\hline
\end{tabular}

determination of higher mode of arbor in free-free and fixed free boundary conditions. The experimentally and numerically obtained results for milling machine arbor are found to have highly better correlation. Some error between the results is introduced by physical dimensions of arbor and variation of material properties data such as young's modulus. The results obtained are well within the acceptable limit (Fig. 11).

\section{Conclusion}

In this study the Modal testing (Experimental modal analysis) and finite element modal analysis of milling machine arbor are performed. Modal testing of the arbor was performed using laser vibrometer and by impact hammer excitation method. In the modal testing it was not feasible to excite the third mode of the milling machine arbor in free-free boundary condition and second mode in fixed-free boundary condition applying by impact hammer excitation method because the arbor has very high stiffness. The numerical results are obtained using the FEM software ANSYS workbench 14.5. The experimentally and numerically obtained results for milling machine arbor are found to have highly better correlation. Some error between the results is received due to minor difference in physical dimensions of arbor and material properties variation. The overall analysis displayed that the results are all well within the acceptable error limit. For future scope, determination of higher modes and corresponding natural frequencies using the sine sweep test can be made. The modal technique presented in this work may be appicable in developing and optimizing the design of machine tools for better cutting conditions.

Fig. 10 Mode shapes and corresponding natural frequencies of arbor in free-free boundary condition 


\section{A: Modal}

Total Deformation 2

Type: Total Deformation

Frequency: $47.944 \mathrm{~Hz}$

$\mathbf{1 . 1 2 6 5}$ Max
1.0014
0.87619
0.75102
0.62585
0.50068
0.37551
0.25034
0.12517
0 Min
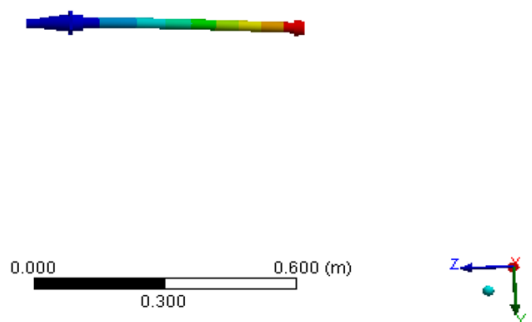

(a)


(b)

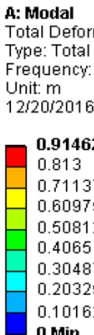

Moda

al Deformation 6

Yype: Total Deformation

0.71137

0.50812

0.30487

0.10162

0.10162
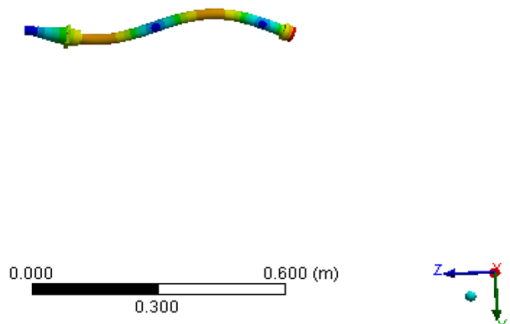

(c)

Fig. 11 Mode shapes and corresponding natural frequencies of arbor in fixed-free boundary condition

\section{Compliance with ethical standards}

Conflict of interest On behalf of all authors, the corresponding author states that there is no conflict of interest.

\section{References}

1. Miller R, Miller MR (2004) Machine shop tools and operations, 5th edn. Willey, Hoboken

2. Patwari AU, Faris WF, Nurul Amin AKM, Loh SK (2009) Dynamic modal analysis of vertical machining centre components. Adv Acoust Vib 2009:1-10. https://doi.org/10.1155/2009/508076

3. Pedrammehr S, Farrokhi H, Rajab AKS, Pakzad S, Mahboubkhah M, Ettefagh MM, Sadeghi MH (2012) Modal analysis of the milling machine structure through FEM and experimental test. Adv Mater Res 383-390:6717-6721. https://doi.org/10.4028/www. scientific.net/AMR.383-390.6717

4. Xiao F, Liu XL, Wang YX, Liu LJ, Qu D (2012) The experimental modal analysis of high speed machining tool system based on integral polynomial recognition method. Mater Sci Forum 723:159-163. https://doi.org/10.4028/www.scientific.net/ MSF.723.159

5. Jamil N, Yusoff AR, Mansor MH (2014) Response prediction of static modal testing on milling machine tool. Appl Mech Mater 606:131-135. https://doi.org/10.4028/www.scientific.net/ AMM.606.131

6. Jamil N, Yusoff AR, Mansor MH (2014) Experimental study of the static modal analysis on milling machine tool. Adv Mater Res 903:123-128. https://doi.org/10.4028/www.scientific.net/ AMR.903.123

7. Cao Y, Altintas $Y$ (2007) Modeling of spindle-bearing and machine tool systems for virtual simulation of milling operations. Int J Mach Tools Manuf 47:1342-1350. https://doi. org/10.1016/j.ijmachtools.2006.08.006

8. Bao Rong, Xiaoting Rui, Guoping Wang (2011) Modified finite element transfer matrix method for eigenvalue problem of flexible structures. J Appl Mech 78:021016-1-021016-7

9. Sandro Barone, Paolo Neri, Alessandro Paoli, Viviano Razionale Armando (2019) Low-frame-rate single camera system for 3D full-field high-frequency vibration measurements. Mech Syst Signal Process 123:143-152

10. Joel Galos, Afaghi Khatibi Akbar, Mouritz Adrian P (2019) Vibration and acoustic properties of composites with embedded lithium-ion polymer batteries. Compos Struct 220:677-686

11. Peter Olsen, Martin Juul, Rune Brincker (2019) Condensation of the correlation functions in modal testing. Mech Syst Signal Process 118:377-387

12. Castillo MA, Gutiérrez RHR, Monteiro UA, Minette RS, Vaz LA (2019) Modal parameters estimation of an electrical submersible pump installed in a test well using numerical and experimental analysis. Ocean Eng 176:1-7

13. Kandil KSA, Saudi GN, Eltaly BA, El-khier MMA (2016) Seismic response of a full-scale wind turbine tower using experimental and numerical modal analysis. Int J Adv Struct Eng 8:337-349. https://doi.org/10.1007/s40091-016-0130-0

14. Ewins DJ (2000) Modal testing: theory, practice and application, 2nd edn. Wiley, Hoboken

15. Maia NMM, Silva JMM (1997) Theoretical and experimental modal analysis. Research Studies Press LTD, Taunton

16. Sw Doebling, Farrar CR, Prime MB (1998) A summary review of vibration-based damage identification techniques. Shock Vib Digest 30:91-105 
17. Friswell M, Mottershead JE (1995) Finite element model updating in structural dynamics. Springer, Berlin

18. Polytec Laser Vibrometer Theory Manual, Polytec, Germany

19. Avitabile P (1998) Could you explain the difference between time domain, frequency domain and modal space. Experimental Techniques
20. Sujatha C (2010) Vibration and acoustics. Tata McGraw-Hill Publication, New Delhi

Publisher's Note Springer Nature remains neutral with regard to jurisdictional claims in published maps and institutional affiliations. 